\title{
A Preliminary Study on Aerated Geopolymer using Calcium Carbide
}

\author{
T. Raghunathan, P. R. Maniarasu, A. Ramasubramanian \\ Department of Civil Engineering, P.A.C. Ramasamy Raja Polytechnic College, \\ Rajapalayam, Tamil Nadu, India
}

\begin{abstract}
In this paper a preliminary study is conducted on use of calcium carbide as an aerator in geopolymer paste and mortar. A 12 mole sodium hydroxide with sodium silicate solution was mixed with fly ash in $1: 2$ ratio to create geopolymer paste. To make mortar, graded sand was used as 3-parts with 1-part paste. Calcium carbide was added in various percentages viz $1 \%, 2 \%$, $3 \%, 4 \%$ and $5 \%$ to paste as first trial and mortar as second trial. Calcium carbide reacts with water to produce acetylene gas and heat. Acetylene gas works as aerator and heat developed helps in ambient curing of geopolymer paste and mortar. The mixes are cast into cubes of $50 \mathrm{sqcm}$ and properties such as density, water absorption and compressive strength were evaluated. The $3 \%$ calcium carbide paste showed less density, more water absorption and less compressive strength. The mortar's density was hovering around $1800 \mathrm{~kg} / \mathrm{m} 3$, water absorption was less than paste and compressive strength was maximum for $4 \%$ calcium carbide.
\end{abstract}

Keyword: Geopolymer; aerated concrete; calcium carbide; acetylene gas; mortar

\section{INTRODUCTION}

\section{A. Aerated Concrete}

Aerated concrete using aluminium powder has been widely produced and researched by our scientific community. Mohd. Mustafa Al Bakri Abdullah Et al. [1] have studied aerated concrete using sulphoaluminate using premixing method.

Sanjayan et al. [2] investigated properties of lightweight geopolymer specimens aerated by aluminium powder. It has been established well that aluminium powder can be appropriately used for foaming of traditional concrete. Reaction between aluminium powder and alkali activator in geopolymers of this study caused high porous structures based on the weight ratios of constituent materials.

In this paper we have tried calcium carbide powder $\left(\mathrm{CaC}_{2}\right)$ as a gas forming agent or as aerator. Till now only calcium carbide residue i.e. calcium oxide is used in concrete. [3][4] The Calcium carbide reacts with water in geopolymer paste to produce acetylene gas which creates the bubbles.

$\mathrm{CaC}_{2}(\mathrm{~s})+2 \mathrm{H}_{2} \mathrm{O}(\mathrm{l})--->\mathrm{Ca}(\mathrm{OH})_{2}(\mathrm{aq})+\mathrm{C}_{2} \mathrm{H}_{2}(\mathrm{~g})$

These bubbles create aerated geopolymer paste or mortar. The heat is generated during acetylene gas production within the paste or mortar, which in turn can be used for curing geopolymer in ambient conditions instead of widely used method of oven curing.

\section{B. Geopolymer}

Geopolymers were first mentioned by Davidovits [5] in the early 1970s to describe inorganic materials with polymeric $\mathrm{Si}-\mathrm{O}-\mathrm{Al}$ bonds obtained from the chemical reaction of alumino -silicate oxides with alkali silicates. The network is made up with $\mathrm{SiO} 4$ and AlO4 tetrahedral linked alternately by sharing all oxygen atoms. The Al3+ in IV-fold coordination becomes a network forming but requires extra charge to compensate, which forces the presence of cations in the framework to balance the structure. According to Davidovits, the empirical formula of geopolymer or poly-sialates is as follows:

$$
\mathrm{Mn}\left\{-\left(\mathrm{SiO}_{2}\right) \mathrm{z}-\mathrm{AlO}_{2}\right\} \text { n-wH } \mathrm{H}_{2} \mathrm{O}
$$


International Journal of Trend in Scientific Research and Development (IJTSRD) ISSN: 2456-6470
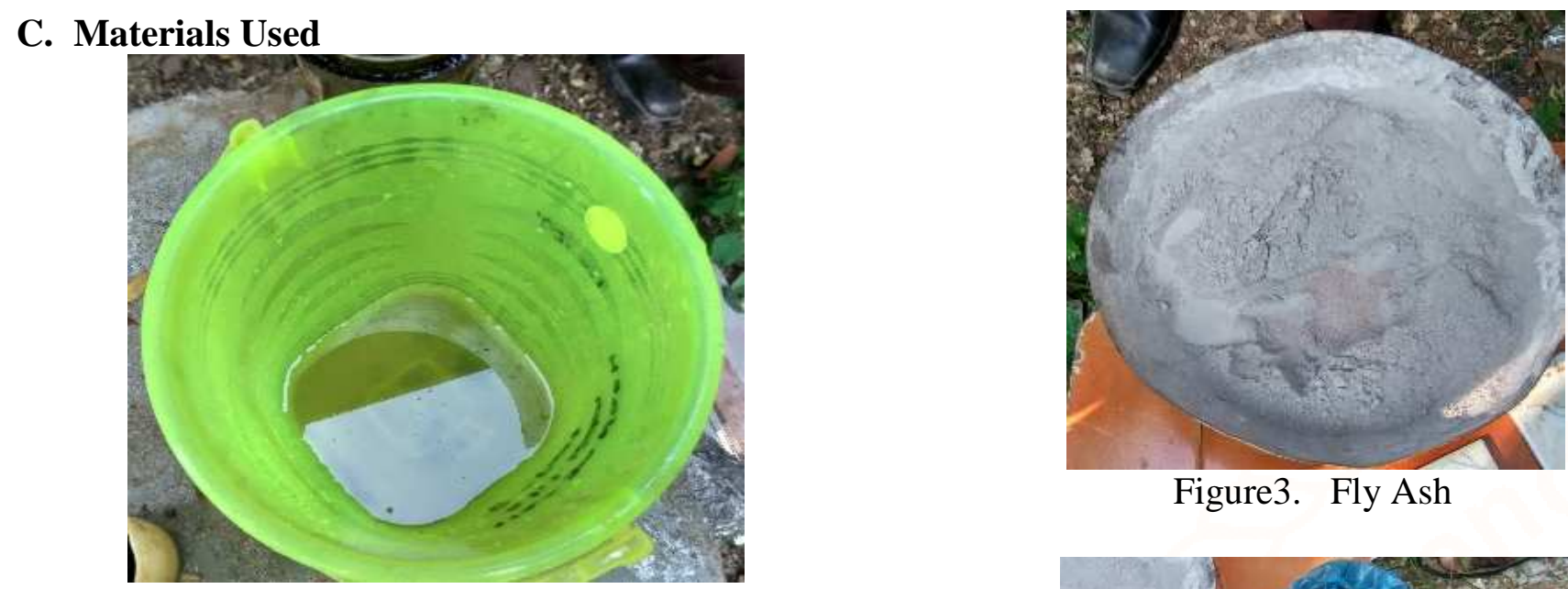

Figure3. Fly Ash

Figure1. Geopolymer Solution

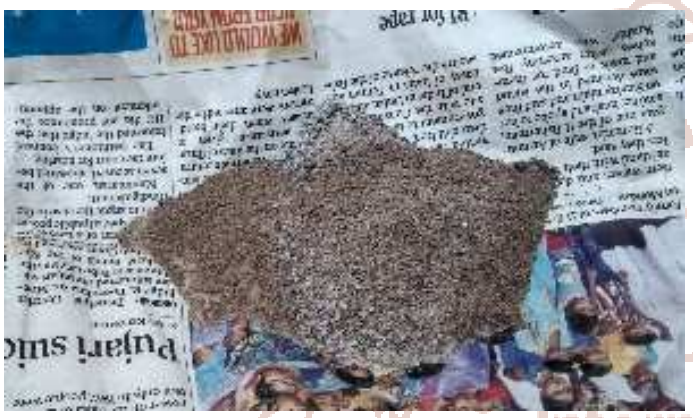

Figure2. Calcium Carbide

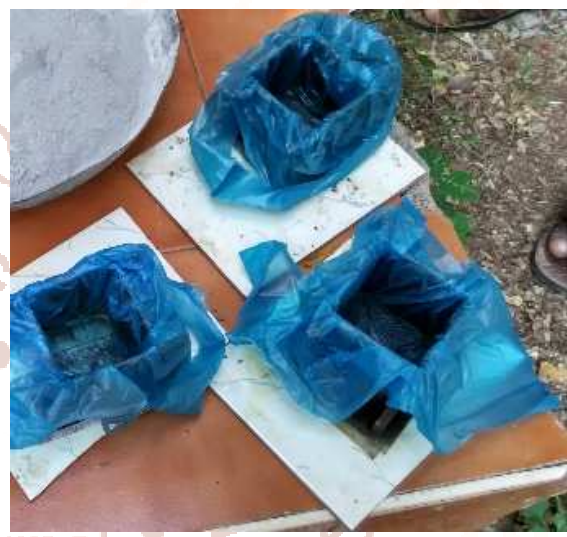

Figure4. Casting Cube Moulds $50 \mathrm{~cm}^{2}$

\section{METHODOLOGY}

Prepare 12 mole
sodium hydroxide
solutions; add sodium
silicate as 1 part to 2-
part Sodium
hydroxide solution 24
hours before casting

To make Mortar, add paste as 1 part to 3 parts of graded sand, then add Calcium carbide $\left(\mathrm{CaC}_{2}\right)$ in various

To make paste, add fly ash as

2 parts to 1 part solution of sodium hydroxide and sodium silicate, then add Calcium carbide $\left(\mathrm{CaC}_{2}\right)$ in various percentages

To make Mortar, add paste as
1 part to 3 parts of graded
sand, then add Calcium
carbide $\left(\mathrm{CaC}_{2}\right)$ in various

\section{PROPERTIES OF MATERIALS USED}

\section{A. Property of sand.}

Specific gravity of sand used is $=2.71$. Natural Graded sand passing through $2.4 \mathrm{~mm}$ and retained in $1.2 \mathrm{~mm}$ sieve is used

\section{B. Property of Fly ash}

Specific Gravity of fly ash $=1.89$

Fineness modulus of flyash $=1.69$

\section{Properties of water}

Total dissolved solids in water $=66 \mathrm{ppm}$

Chlorides in water $=57 \mathrm{ppm}$

$\mathrm{pH}$ of water $=7 \mathrm{ppm}$
Casting of 50 sq. $\mathrm{cm}$ cubes and 3 days ambient curing

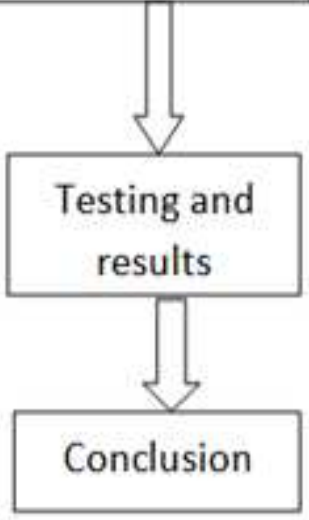


International Journal of Trend in Scientific Research and Development (IJTSRD) ISSN: 2456-6470

\section{TEST RESULTS}

\begin{tabular}{|c|c|c|}
\multicolumn{2}{|c}{ TABLE.I DENSITY } \\
\hline \multirow{2}{*}{ Mix } & Density In Kg/M & \\
\cline { 2 - 3 } & Paste & Mortar \\
\hline $\mathrm{CaC}_{2}-1 \%$ & 1258.49 & 1825.01 \\
\hline $\mathrm{CaC}_{2}-2 \%$ & 1137.02 & 1710.39 \\
\hline $\mathrm{CaC}_{2}-3 \%$ & 739.06 & 1744.4 \\
\hline $\mathrm{CaC}_{2}-4 \%$ & 894.06 & 1865.88 \\
\hline $\mathrm{CaC}_{2}-5 \%$ & 1414.47 & 1817.29 \\
\hline
\end{tabular}

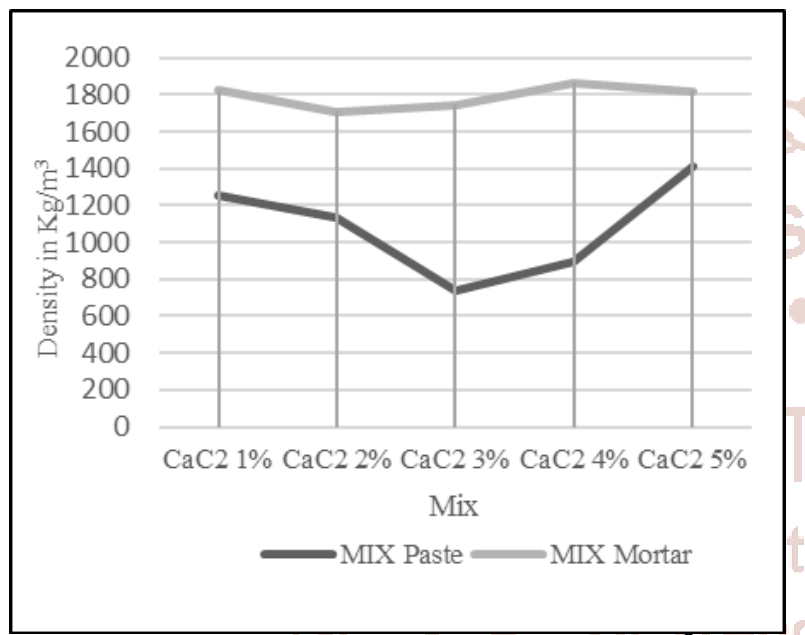

Figure 5. Density of Mixes in $\mathrm{Kg} / \mathrm{m}^{3}$

TABLE.II Water absorption

\begin{tabular}{|c|c|c|}
\hline \multirow{2}{*}{ Mix } & Water absorption in percentage \\
\cline { 2 - 3 } & Paste & Mortar \\
\hline $\mathrm{CaC}_{2}-1 \%$ & 4.99 & 5.613 \\
\hline $\mathrm{CaC}_{2}-2 \%$ & 1.82 & 7.1 \\
\hline $\mathrm{CaC}_{2}-3 \%$ & 17.86 & 6.4 \\
\hline $\mathrm{CaC}_{2}-4 \%$ & 12.2 & 5.47 \\
\hline $\mathrm{CaC}_{2}-5 \%$ & 11.23 & 6.67 \\
\hline
\end{tabular}

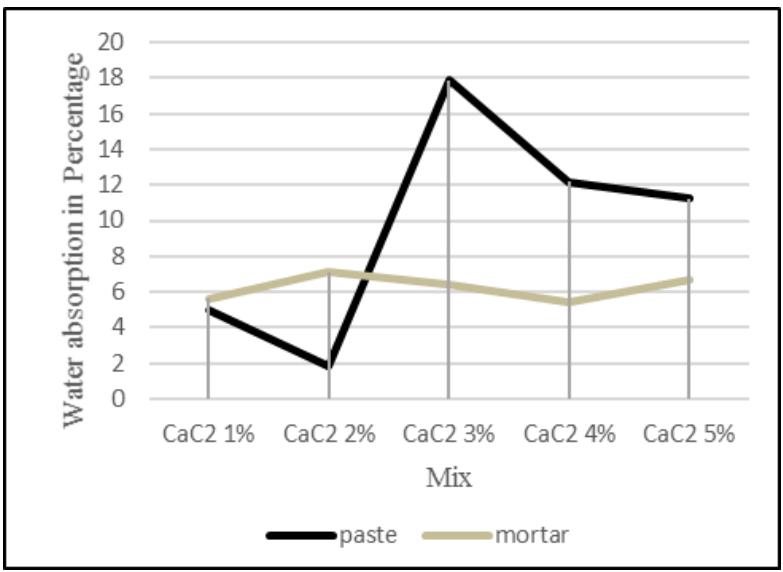

Figure6. Water Absorption of Mixes in Percentage TABLE.III Compressive Strength

\begin{tabular}{|c|c|c|}
\hline \multirow{2}{*}{ Mix } & \multicolumn{2}{|c|}{ Compressive strength in $\mathrm{N} / \mathrm{mm}^{2}$} \\
\cline { 2 - 3 } & Paste & Mortar \\
\hline $\mathrm{CaC}_{2}-1 \%$ & 4.71 & 1.88 \\
\hline $\mathrm{CaC}_{2}-2 \%$ & 0.77 & 2.54 \\
\hline $\mathrm{CaC}_{2}-3 \%$ & 0.752 & 3.55 \\
\hline $\mathrm{CaC}_{2}-4 \%$ & 1.35 & 5.33 \\
\hline $\mathrm{CaC}_{2}-5 \%$ & 3.04 & 1.422 \\
\hline
\end{tabular}

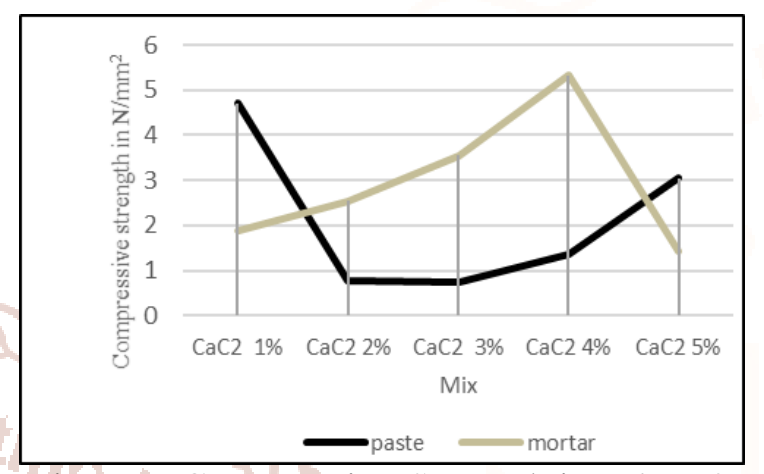

Figure7. Compressive Strength in N/mm2

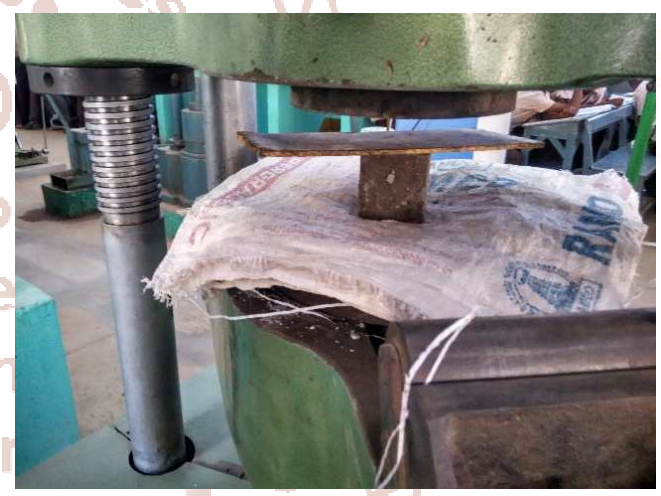

Figure8. Before Compression Test

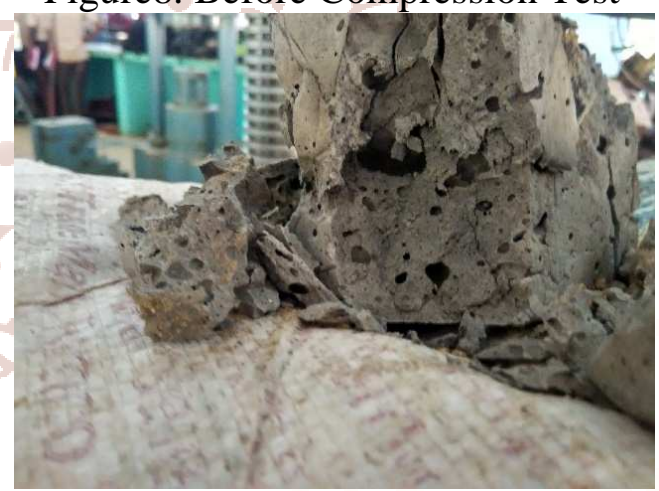

Figure9. After Compression Test

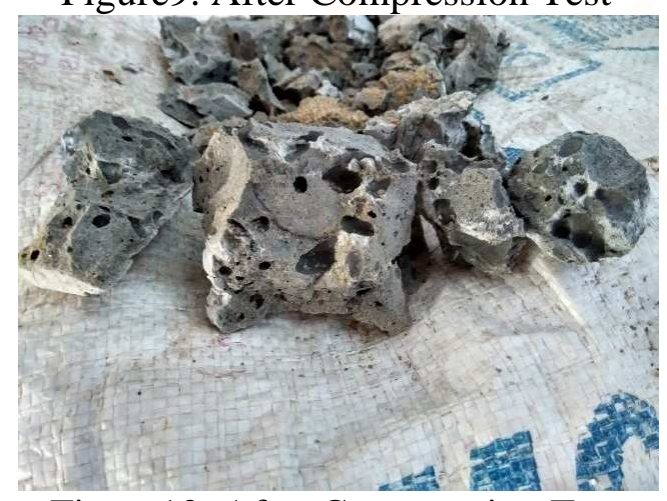

Figure10. After Compression Test 


\section{CONCLUSION}

$>$ In Geopolymer Paste, the minimum Density is given by $3 \%$ of Calcium Carbide. The density is $739 \mathrm{~kg} / \mathrm{m} 3$. In Geopolymer Mortar, the minimum Density is given by $2 \%$ of Calcium Carbide. The density is $1710 \mathrm{~kg} / \mathrm{m} 3$. So paste gives lower density compared to mortar. Hence paste with $3 \%$ calcium carbide can be effectively used for low dead weight infill walls and other similar applications

$>$ The minimum water absorption is given by $2 \%$ of Calcium Carbide in paste and $4 \%$ of Calcium Carbide in mortar. The highest water absorption in in Geopolymer paste with 3\% Calcium carbide. This correlates with the low density of same mix and hence more voids.

$>$ The maximum Strength is given by $1 \%$ of Calcium Carbide in paste. The mixes 2\%,3\% of calcium carbide in paste show a lower compressive strength, which correlates with low density and high water absorption of $3 \%$ calcium carbide paste results. The maximum compressive strength is given by $4 \%$ calcium carbide in mortar. If compressive strength is not major criteria for infill wall application, then the Aerated Geopolymer Using Calcium Carbide may be a future composite in aerated precast products.

\section{REFERENCES}

1. Mohd. Mustafa Al Bakri Abdullah, Kamarudin Hussin, Mohamed Bnhussain, Khairul Nizar Ismail, Zarina Yahya,and Rafiza Abdul Razak, "Fly Ash-based Geopolymer Lightweight Concrete Using Foaming Agent" Int J Mol Sci. 2012; 13(6):pp7186-7198.

2. Sanjayan, Jay G.; Nazari, Ali; Chen, Lei; Nguyen, Giang Hoang "Physical and mechanical properties of lightweight aerated geopolymer" Elsevier, Construction and Building Materials, Volume 79 - Mar 15, 2015, pp236-244

3. Nattapong Makaratat; Chai Jaturapitakkul; and Thanapol Laosamathikul, "Effects of Calcium Carbide Residue-Fly Ash Binder on Mechanical Properties of Concrete" Journal of Materials in Civil Engineering/Volume 22 Issue 11 November 2010

4. Chaiyanunt Rattanashotinunt, PongsiriThairit, Weerachart Tangchirapat, ChaiJaturapitakkul "Use of calcium carbide residue and bagasse ash mixtures as a new cementitious material in concrete" Elsevier, Materials \& Design. Volume 46, April 2013, Pages 106-111

5. J. Davidovits, Emeritus Professor, Geopolymer Institute, Saint-Quentin, France, geopolymer.org 